
\title{
25 Research Soure \\ Nutrient Leaching in Extensive Green Roof Substrate Layers With Different Configurations
}

\section{Chen Xu}

Nanchang University School of Civil Engineering and Architecture https://orcid.org/0000-0003-29734043

\section{Zaohong Liu}

Nanchang University School of Civil Engineering and Architecture

\section{Guanjun Cai}

Nanchang University School of Civil Engineering and Architecture

Jian Zhan ( $D$ zhanjian@ncu.edu.cn )

Nanchang University

\section{Research Article}

Keywords: Extensive green roof, substrate layer, nutrients leaching, configuration, rainfall runoff, pollution interception.

Posted Date: July 21st, 2021

DOl: https://doi.org/10.21203/rs.3.rs-601414/v1

License: (c) (i) This work is licensed under a Creative Commons Attribution 4.0 International License. Read Full License

Version of Record: A version of this preprint was published at Environmental Science and Pollution Research on January 17th, 2022. See the published version at https://doi.org/10.1007/s11356-02117969-3. 
1 Nutrient Leaching in Extensive Green Roof 2 Substrate Layers with Different Configurations

3 Chen $\mathrm{Xu}^{1}$ Zaohong Liu ${ }^{1}$ Guanjun Cai ${ }^{1} \mathrm{Jian}_{\mathrm{Zhan}}{ }^{2}$

4 1. School of Civil Engineering and Architecture, Nanchang University, Nanchang 330031, China

5 2. School of Resources, Environmental \& Chemical Engineering and Key Laboratory of Poyang

6 Lake Environment and Resource Utilization, Ministry of Education, Nanchang University,

7 Nanchang 330031, China

8 Correspondence author: Jian Zhan; email: zhanjian@ ncu.edu.cn.

\section{$9 \quad$ Highlights}

Multiple adsorption substrates have a synergistic effect on the adsorption and interception of pollutants.

Layered substrate layer have significant $\mathrm{NH}_{4}{ }^{+}-\mathrm{N}$ interception capacity due to the unique lower adsorption layer.

The addition of polyacrylamide in EGR substrate layer is likely to cause additional nitrogen pollution.

Biochar can be used as an excellent modifier to enhance the rainfall runoff pollution interception capacity of EGRs.

\section{Declarations}

Ethics approval and consent to participate: Not applicable

Consent for publication: Not applicable

Availability of data and materials: The datasets used and analyzed during the current study are available from the corresponding author on reasonable request

Competing interests: The authors declare that they have no competing interests

Funding: This work was supported by the Special Fund for Postgraduate Innovation in Jiangxi Province, China [Grant No.YC2020-S125]; the Postgraduate Innovation Project of Nanchang University, China [Grant No.CX2019115].

Authors' contributions: All authors contributed to the study conception and design. Material preparation, data collection and analysis, tables and figures drawing were performed by Chen Xu, Zaohong Liu and Guanjun Cai. The first draft of the manuscript was written by Chen Xu and all authors commented on previous versions of the manuscript. Jian Zhan revised the manuscript critically for important intellectual content. All authors read and approved the final manuscript.

Acknowledgements: Not applicable 
Due to substrate layers with different substrate configurations, extensive green roofs (EGRs) exhibit different rainfall runoff retention and pollution interception effects. In the rainfall runoff scouring process, nutrient leaching often occurs in the substrate layer, which becomes a pollution source for rainwater runoff. In this study, six EGR devices with different substrate layer configurations were fabricated. Then, the cumulative leaching quantity (CLQ) and total leaching rate (TLR) of $\mathrm{NH}_{4}{ }^{+}, \mathrm{TN}$ and TP in the outflow of nine different depth simulated rainfall events under local rainfall characteristics were evaluated and recorded. Furthermore, the impact of different substrate configurations on the pollution interception effects of EGRs for rainfall runoff was studied. Results show that a mixed adsorption substrate in the EGR substrate layer has a more significant rainfall runoff pollution interception capacity than a single adsorption substrate. PVL and PVGL, as EGRs with layered configuration substrate layers, exhibited good $\mathrm{NH}_{4}{ }^{+}-\mathrm{N}$ interception capacity. The CLQ and TLR of $\mathrm{NH}_{4}{ }^{+} \mathrm{N}$ for PVL and PVGL were $-114.613 \mathrm{mg}$ and $-63.43 \%,-121.364 \mathrm{mg}$ and $-67.16 \%$, respectively. Further, the addition of biochar as a modifier significantly slowed down the substrate layer TP leaching effect and improved the interception effect of $\mathrm{NH}^{+}-\mathrm{N}$ and $\mathrm{TN}$. Moreover, although polyacrylamide addition in the substrate layer aggravated the nitrogen leaching phenomenon in the EGRs outflow, but the granular structure substrate layer constructed by it exhibited a significantly inhibited TP leaching effect.

Keywords: Extensive green roof; substrate layer; nutrients leaching; configuration; rainfall runoff; pollution interception.

\section{Introduction}

In recent years, the urbanization process in China has accelerated, and the hardening rates of roads and roofs have sharply increased. Simultaneously, extreme rainstorms have frequently occurred, causing a large number of pollutants to be washed away by runoff into receiving water. This has led to urban waterlogging and non-point source pollution phenomena. As an important low-impact development and sponge city measure, green roofs (GRs) have a certain mitigation effect on urban waterlogging and non-point source pollution problems that need to be urgently solved (Zhou et al. 2019; Abualfaraj et al. 2018; Shafique et al. 2018; Todorov et al. 2018). Extensive GRs (EGRs), as a simple-structured GR form with low cost and easy maintenance, have been widely applied in practical engineering application and academic research by scholars worldwide (Thuring et al. 2019; Gong et al. 2019). Most relevant research results show that the substrate layer is the most significant factor affecting the rainfall runoff retention and pollution interception capacities of EGRs (Gong et al. 2018; Hill et al. 2019; Liu et al. 2019). Therefore, systematic research on the rainfall runoff retention and pollution interception capacities of the substrate layer is of great significance to the future construction, application and promotion of EGRs.

The substrate layer composition can be divided into three parts: substrate type, ratio and configuration. Currently, numerous studies exist on the substrate type and ratio (Eksi et al. 2016; Santos et al. 2018), but few studies exist on the EGRs substrate configuration. The effects of 
different substrate configuration methods on the rainfall runoff retention and pollution interception capacities of EGRs are still unclear. Thus, the substrate configuration methods of the EGR substrate layer need to be systematically studied.

Numerous researchers have reached a consensus and have verified through practical engineering applications and experimental studies that the EGR substrate layer can effectively delay outflow, retain runoff and reduce peak flow during the rainfall process (Vijayaraghavan et al. 2019; Gong et al. 2018). However, due to the different substrate types, ratios and configurations, the pollution interception effectiveness of EGRs for rainfall runoff is quite different and often appears as a pollution source for rainfall runoff (Karczmarczyk et al. 2018; Chai et al. 2018; Zhang et al. 2018). This is because of the leaching of the nutrients in the substrate layer during the runoff scouring process. Moreover, the contact time between runoff and adsorption substrate is extremely short and cannot effectively exert its adsorption capacity for pollutants, causing an increase in the concentration of pollutants in the outflow. For EGR to effectively intercept pollution in rainfall runoff, instead of becoming a pollution source of rainfall runoff, the nutrient leaching of the substrate layers during the rainfall process need to be controlled.

In this study, six EGR experimental devices with different substrate configurations are fabricated to investigate the leaching effectiveness of $\mathrm{NH}_{4}{ }^{+} \mathrm{N}, \mathrm{TN}$ and $\mathrm{TP}$ in the EGR substrate layer with different substrate configurations in nine simulated rainfall events under three rainfall grades of heavy rain, torrential rain and downpour. Furthermore, the influencing effects of nutrient leaching control capabilities in EGRs with different configurations are analyzed. This study provides a reliable basis and reference for constructing of EGRs and EGR substrate layers in practical engineering applications and experimental research.

\section{Method}

\section{Study Area}

The study area is located in the School of Civil Engineering and Architecture, Qianhu Campus, Nanchang University, Nanchang, Jiangxi Province, People's Republic of China. The EGR devices were built on the roof of the School of Architecture and Engineering of Nanchang University, and July-September 2020 was the construction and maintenance period of the EGR devices. During the entire construction and maintenance period, all EGR devices performed well and vegetation growths were luxuriant. The simulated rainfall experiments were performed in the laboratory of the School of Architecture and Engineering of Nanchang University to ensure identical experimental environment for all EGR devices and to avoid the influence of variables other than the experiment on the results. The experiment period was from October to November 2020 .

\section{Devices Construction}

In this study, six experimental devices were fabricated using polyvinyl chloride (PVC); they are uncovered cuboids with dimensions of $50 \mathrm{~cm} \times 50 \mathrm{~cm} \times 30 \mathrm{~cm}$. Two outlet holes with 
diameters of $2 \mathrm{~cm}$ and placed $20 \mathrm{~cm}$ apart, were connected with a suitable length of plastic hose to facilitate the collection of the outlet samples.

The vegetation layer of the EGR devices was the Sedum lineare Thunb, and it was uniformly transplanted. Most vegetation height was $5-10 \mathrm{~cm}$, and the vegetation planting density was about $400 / \mathrm{m}^{2}$. Sedum lineare Thunb has the characteristics of short roots, good wind resistance and strong drought tolerance, which meets the requirements of vegetation selection in EGR construction (Tuttolomondo et al. 2018). Furthermore, Sedum lineare Thunb is a local vegetation species with good long-term growth and low cost. Stephanie et al. (2019) showed that Sedum lineare Thunb performs best under the single cultivation method, which is according to the trend of EGR continuous development. Herein, the substrate layer configuration methods employed are direct mixing, layered configuration and modifier addition. Direct mixing refers to evenly mixing the nutrient and adsorption substrates through stirring and directly configuring them as the EGR substrate layer. Layered configuration refers to the separation of the nutrient and adsorption substrates using non-woven geotextile. The upper nutrient substrate layer provides the nutrients needed for the growth of the vegetation layer, while the lower adsorption substrate layer relies on the unique physical and chemical characteristics of the substrate for rainfall runoff retention and pollution interception effects. Modifier addition is based on direct mixing and a modifier is added in the substrate layer for improving the substrate layer structure to enhance the water retention performance of the substrate layer while inhibiting the nutrient leaching effect. For the substrate layer, peat soil is uniformly selected as the nutrient substrate for the normal vegetation growth, and vermiculite and green zeolite are selected as the adsorption substrate. The substrate layer modifier comprises biochar and polyacrylamide (PAM). The addition of biochar in the EGR substrate layer can effectively reduce the bulk density, increase the porosity of the substrate layer and improve the environmental adaptability of vegetation to substrate (Ouyang et al. 2016; Huang et al. 2020; Chen et al. 2018). PAM has strong cohesiveness. Moreover, the addition of PAM to the EGR substrate layer can effectively promote the formation of soil aggregates between the nutrient and adsorption substrates and reduce the nutrient leaching during the runoff erosion process (Sepaskhah et al.2010). The combinations of the nutrient and adsorption substrates employed herein possess low volume density, which meets the requirements of roof load in practical engineering applications and experimental studies; thus, the substrate layer thickness was set to 20 $\mathrm{cm}$. The filter layer was composed of permeable non-woven geotextile to prevent rainfall runoff from penetrating through the substrate layer and entraining fine particles, which increase turbidity or other pollutants in the effluents. A hard drainage board was adopted by the drainage layer to ensure that the rainfall runoff that cannot be retained in the substrate layer can be smoothly discharged and to avoid the overflow phenomenon that good vegetation growth. The composition and physical properties of the substrate layers in the six EGR devices with different substrate configurations methods are presented in Table 1.

Table 1 The composition and physical properties of the six EGR devices substrate layers

\begin{tabular}{|c|c|c|c|c|c|}
\hline \multirow[b]{2}{*}{ Devices } & \multirow[b]{2}{*}{ Substrate Composition } & \multirow{2}{*}{$\begin{array}{c}\text { Substrate } \\
\text { Configuration }\end{array}$} & \multicolumn{3}{|c|}{ Physical Properties } \\
\hline & & & $\begin{array}{l}\text { Volume Weight } \\
\qquad\left(\mathrm{N} / \mathrm{m}^{3}\right)\end{array}$ & $\begin{array}{l}\text { Specific } \\
\text { Gravity }\end{array}$ & $\begin{array}{c}\text { Porosity } \\
(\%)\end{array}$ \\
\hline PV & $30 \%$ peat soil $+70 \%$ vermiculite & Direct mixing & 2918.61 & 1.37 & 78.26 \\
\hline PVL & $30 \%$ peat soil & Layered & 5739.28 & 1.56 & 62.52 \\
\hline
\end{tabular}




\begin{tabular}{|c|c|c|c|c|c|}
\hline & $70 \%$ vermiculite & & 1704.16 & 1.16 & 85.01 \\
\hline PVB & $\begin{array}{c}30 \% \text { peat soil }+70 \% \text { vermiculite } \\
\text { (5\% biochar) }\end{array}$ & $\begin{array}{l}\text { Modifier } \\
\text { addition }\end{array}$ & 3043.48 & 1.27 & 75.53 \\
\hline PVG & $\begin{array}{l}30 \% \text { peat soil }+30 \% \text { vermiculite } \\
\quad+40 \% \text { green zeolite }\end{array}$ & Direct mixing & 6448.37 & 1.67 & 60.58 \\
\hline & $30 \%$ peat soil & & 5739.28 & 1.56 & 62.52 \\
\hline PVGL & $\begin{array}{c}30 \% \text { vermiculite }+40 \% \text { green } \\
\text { zeolite }\end{array}$ & Layered & 6752.26 & 1.72 & 59.92 \\
\hline PVGP & $\begin{array}{l}30 \% \text { peat soil }+30 \% \text { vermiculite } \\
+40 \% \text { green zeolite }(1 \% \text { PAM })\end{array}$ & $\begin{array}{l}\text { Modifier } \\
\text { addition }\end{array}$ & 6401.95 & 1.66 & 60.62 \\
\hline
\end{tabular}

The six EGR devices with different substrate configurations are shown in Fig 1.

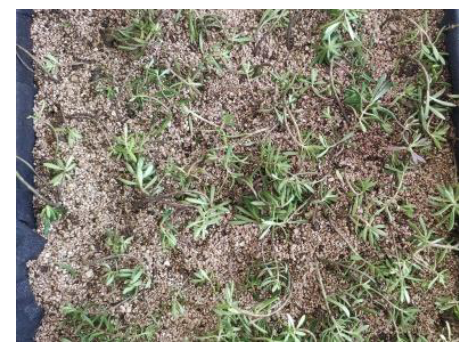

(a) PV

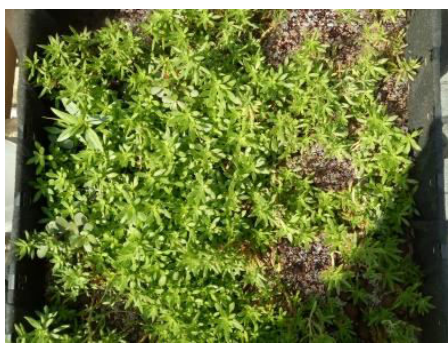

(e) PVG

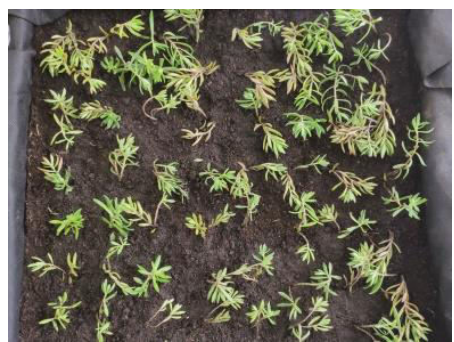

(b) PVL

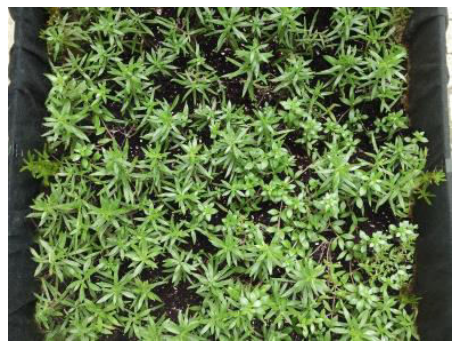

(e) PVGL

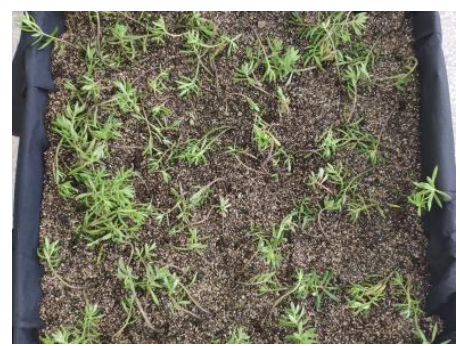

(c) PVB

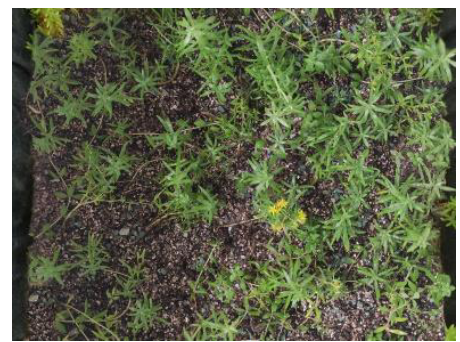

(f) PVGP

Fig 1 The six EGR devices with different substrate configurations

\section{Simulated Rainfall Design}

The simulated rainfall depth and quality were selected herein according to the Nanchang rainfall characteristics. The single-day rainfall data were collected in Nanchang for the past five years (2015 to 2019) by the National Meteorological Science Data Centre. According to the national standard of the People's Republic of China 'GB/T 28592 - 2012 Precipitation grade', the grades of the rainfall events were classified and counted, and the total number of rainfall events and the number of rainfall events for each grade in Nanchang were recorded for each year. Most of the rainfall events in the past five years were light and moderate rain, accounting for $86 \%-88.57 \%$ of the total rainfall days in the past five years. However, some researchers have indicated that EGRs can reach a retention rate of $75 \%-99.6 \%$ in light and moderate rain events, and that continuous rainfall events do not affect the rainfall runoff retention performance of EGRs (Zhou et al. 2019; Huang et al. 2018). Therefore, more attention should be paid to the rainfall retention capacity of EGRs during heavy and continuous rainfall events. In this study, based on the 
proportions of the three rainfall grades of heavy rain, torrential rain and downpour in Nanchang in the past five years, six heavy rain events, two torrential rain events and a downpour event were selected as simulated rainfall depths. By arranging the rainfall depths of the three rainfall grades in the past five years in ascending order, the rainfall depths of each grade were screened based on the quantile and the simulated rainfall depths were determined: the depths of six heavy rains are 25.5, $27.3,30.8,32.2,36.7,43.3 \mathrm{~mm}$; those of two torrential rains are 68.8 and $89.5 \mathrm{~mm}$ and that of one downpour is $128.05 \mathrm{~mm}$.

According to the short-duration and high-intensity rainfall characteristics in Nanchang and considering the study by Dimitar et al. (2018), when the interval of the rainfall events is greater than two days, the rainfall runoff retention capacity of the EGR substrate layer will not be affected by the last rainfall event. Thus, herein, the antecedent dry period (ADP) of the experimental devices was set to two days, the simulated rainfall duration was set to $2 \mathrm{~h}$ and the simulated rainfall type was uniform distribution.

From May to July 2020, a simple rain gauge was used on the roof to collect natural rainwater samples from ten rainfall events. The water quality of $\mathrm{NH}_{4}{ }^{+}-\mathrm{N}, \mathrm{TN}$ and $\mathrm{TP}$ in the samples was measured within $24 \mathrm{~h}$. The indicators were tested and analyzed, and the specific results are shown in Table 2.

Table 2 Rainwater quality of ten natural rainfall events

\begin{tabular}{cccccc}
\hline Date & Rainfall Depth & ADP & \multicolumn{3}{c}{ Rainfall Quality (mg/L) } \\
\cline { 5 - 7 }$(\mathrm{dd} / \mathrm{mm} / \mathrm{yy})$ & $(\mathrm{mm})$ & $(\mathrm{h})$ & $\mathrm{NH}_{4}{ }^{+}-\mathrm{N}$ & $\mathrm{TN}$ & $\mathrm{TP}$ \\
\hline $09 / 05 / 2020$ & 61.8 & 37.6 & 2.25 & 3.99 & 0.17 \\
$15 / 05 / 2020$ & 69 & 113.4 & 2.96 & 5.32 & 0.33 \\
$30 / 05 / 2020$ & 40.5 & 11.1 & 0.61 & 1.87 & 0.10 \\
$03 / 06 / 2020$ & 34.7 & 62.8 & 1.91 & 3.77 & 0.25 \\
$10 / 06 / 2020$ & 25.7 & 10.5 & 1.11 & 2.38 & 0.12 \\
$30 / 06 / 2020$ & 55.7 & 55.5 & 1.45 & 4.82 & 0.22 \\
$01 / 07 / 2020$ & 83.2 & 1.3 & 0.74 & 1.58 & 0.08 \\
$03 / 07 / 2020$ & 61.4 & 28.7 & 1.95 & 3.79 & 0.16 \\
$08 / 07 / 2020$ & 209.3 & 0.6 & 0.88 & 1.71 & 0.07 \\
$10 / 07 / 2020$ & 88.6 & 22.7 & 1.54 & 4.07 & 0.21 \\
\hline
\end{tabular}

Table 2 show that the pollutant indicators of the rainwater samples collected from the ten rainfall events are quite different because of the influence of different rainfall depths, rainfall durations and ADPs. To obtain simulated rainfall quality close the actual rainfall quality and to facilitate the analysis and comparison of the experimental results, the concentrations of each pollutant in the ten natural rainfall events were averaged to determine the simulated rainfall quality. Table 3 presents the simulated rainfall quality.

Table 3 Simulated rainfall quality

\begin{tabular}{cccc}
\hline Measurement & $\mathrm{NH}_{4}{ }^{+}-\mathrm{N}$ & $\mathrm{TN}$ & $\mathrm{TP}$ \\
\hline Concentration $(\mathrm{mg} / \mathrm{L})$ & 1.5 & 3.3 & 0.2 \\
\hline
\end{tabular}

The simulated rainfall water is prepared by adding the corresponding ionic standard solutions in deionized water. Thus, $\mathrm{NH}_{4}{ }^{+}$is prepared by adding an ammonium chloride $\left(\mathrm{NH}_{4} \mathrm{Cl}\right)$ standard solution (containing $1 \mathrm{mg} / \mathrm{ml}$ of nitrogen in the form of ammonia); $\mathrm{TN}$ is prepared by adding potassium nitrate $\left(\mathrm{KNO}_{3}\right)$ standard solution (containing $0.1 \mathrm{mg} / \mathrm{ml}$ of nitrogen in the form of nitrate); TP is prepared by adding monopotassium phosphate $\left(\mathrm{KH}_{2} \mathrm{PO}_{4}\right)$ standard solution 
(containing $50 \mu \mathrm{g} / \mathrm{ml}$ phosphorus).

Moreover, the simulated rainfall device is shown in Fig 2.

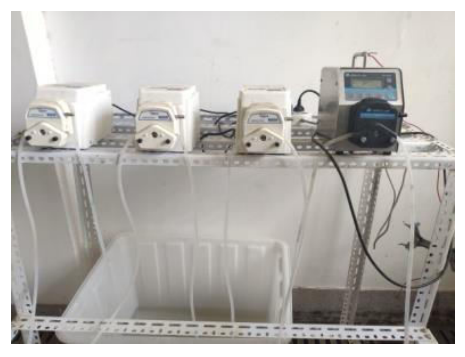

(a) Simulated rainfall experiment platform

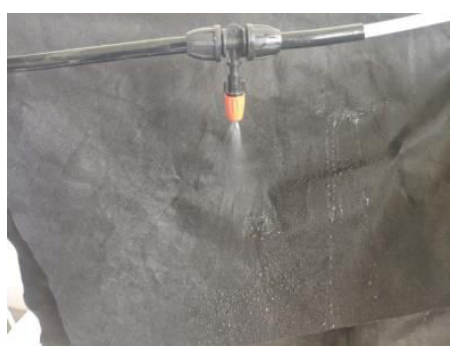

(b) Schematic diagram of atomizer nozzle

Fig 2 Schematic diagram of the simulated rainfall device

The prepared simulated rainfall water was stored in a $160 \mathrm{~L}$ water storage tank. The peristaltic pump squeezed the hose through the rotor to form a negative pressure in the tube, and the water flowed along with it. After the hose was filled with water, the pressurized water was uniformly sprayed on the receiving surface of the devices via atomization through the atomizer nozzle to simulate actual rainfall. This was done to obtain more reliable experimental data. During the entire experiment process, the climatic environment and ADP of each device were maintained at the same value to avoid interference from factors other than the experimental variables.

\section{Sample and Data Collection}

During the simulated rainfall experiment, a polyethylene terephthalate (PET) bucket was set at the outlet of the devices to collect the outflow samples. The timing was recorded from the beginning of the simulated rainfall. The time taken by each device to produces outflow was recorded; the outflow sample in the collection bucket was poured into a graduated cylinder for measurement and record after $5 \mathrm{~min}, 10 \mathrm{~min}$ and every $10 \mathrm{~min}$ interval thereafter till the end of the simulated rainfall. The samples were stored in a refrigerator at $4{ }^{\circ} \mathrm{C}$ and the concentration of related pollutants in the samples was determined within $24 \mathrm{~h}$.

In this study, the concentrations of $\mathrm{NH}_{4}{ }^{+}-\mathrm{N}, \mathrm{TN}$, and $\mathrm{TP}$ in the samples were determined. Nessler's reagent spectrophotometry, alkaline potassium persulfate digestion UV spectrophotometry and ammonium molybdate spectrophotometry were used to determine $\mathrm{NH}_{4}{ }^{+}-\mathrm{N}$, TN, and TP, respectively. The determination methods are based on the current National Standards or the Ministry of Environmental Protection Standards.

The experimental data were processed and analyzed using IBM SPSS Statistics 25.0, Microsoft Excel 2010, and Origin Pro 2018. Due to the uneven variation in the data, the Games-Howell test was used in the one-way analysis of variance to determine the statistical significance of the volume and concentration of pollutants in the various outflow samples. The results indicated that at all data were in accordance with the normal distribution at the level of $\alpha=$ 0.05 . 
nutrient leaching control ability of the EGR substrate layer through two indicators: cumulative leaching quantity (CLQ) and total leaching rate (TLR). CLQ is the cumulative leaching quality of pollutants in a single rainfall event, which can be calculated by the following formula:

$$
C L Q=\int_{0}^{T} C(t) Q(t)-\mathrm{C}_{\mathrm{r}} S D \approx \sum_{i=1}^{n} C_{i} V_{i}-\mathrm{C}_{\mathrm{r}} S D
$$

Where CLQ is the cumulative leaching quantity $(\mathrm{mg}) ; \mathrm{C}(\mathrm{t})$ is the pollutant concentration distribution of the outflow in a rainfall event with time $\mathrm{t}(\mathrm{mg} / \mathrm{L}) ; \mathrm{Q}(\mathrm{t})$ is the outflow volume in a rainfall with time $\mathrm{t}\left(\mathrm{m}^{3} / \mathrm{s}\right)$; $\mathrm{T}$ is the total outflow duration $(\mathrm{s}) ; \mathrm{C}_{\mathrm{r}}$ is the pollutant concentration in the simulated rainfall $(\mathrm{mg} / \mathrm{L}) ; \mathrm{S}$ is the receiving surface area $\left(\mathrm{m}^{2}\right)$; $\mathrm{D}$ is the simulated rainfall depth $(\mathrm{mm}) ; \mathrm{n}$ is the number of outflow time segments; $\mathrm{C}_{\mathrm{i}}$ is the pollutant concentration in an outflow sample collected during the $\mathrm{i}$-th period $(\mathrm{mg} / \mathrm{L}) ; \mathrm{V}_{\mathrm{i}}$ is the volume of the outflow sample collected during the $\mathrm{i}$-th period $\left(\mathrm{m}^{3}\right)$.

TLR is the total leaching rate of pollutants during the whole experiment process, which can be calculated by the following formula:

$$
T L R=\frac{\sum_{\mathrm{i}=1}^{\mathrm{n}} C L Q_{\mathrm{i}}}{\sum_{\mathrm{i}=1}^{\mathrm{n}} \mathrm{C}_{\mathrm{r}} S D_{\mathrm{i}}} \times 100 \%
$$

Where TLR is the total leaching rate (\%); $\mathrm{n}$ is the total number of the simulated rainfall event; $\mathrm{CLQ}_{\mathrm{i}}$ is the cumulative leaching quantity of pollutants in i-th rainfall event $(\mathrm{mg}) ; \mathrm{C}_{\mathrm{r}}$ is the pollutant concentration in the simulated rainfall $(\mathrm{mg} / \mathrm{L}) ; \mathrm{S}$ is the receiving surface area $\left(\mathrm{m}^{2}\right)$; $\mathrm{D}$ is the simulated rainfall depth (mm);

\section{Result and Discussion}

This study measures the volume of the outflow samples and the concentrations of $\mathrm{NH}_{4}{ }^{+} \mathrm{N}$, TN and TP in six EGR devices with different substrate configurations during nine different depth rainfall events. Furthermore, the CLQ of each pollutant in the six EGR devices outflow samples for different rainfall events and the TLR of each pollutant during the entire simulated rainfall process were calculated. Then, the EGR nutrient leaching effect for the different substrate configurations were evaluated and discussed.

The CLQ of each pollutant in the six EGR devices outflow samples during nine different depth rainfall events and the TLR of each pollutant during the entire simulated rainfall process are shown in Figs 3-6. Because of the different substrate configurations, EGRs have different substrate layer structures and physical properties; therefore, the nutrient leaching effects of $\mathrm{NH}_{4}{ }^{+}-\mathrm{N}, \mathrm{TN}$ and TP in the six EGR devices should be different. 


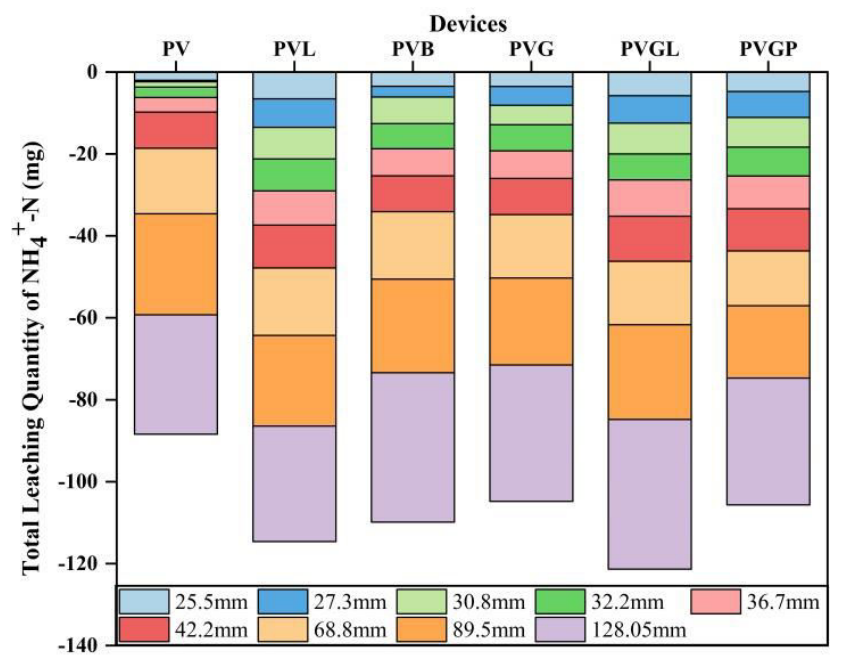

Fig 3 The CLQ of $\mathrm{NH}_{4}{ }^{+}-\mathrm{N}$ in the six EGR devices outflow samples during the nine different depth rainfall events

Fig 3 shows the CLQ of $\mathrm{NH}_{4}{ }^{+}-\mathrm{N}$ in the six EGR devices outflow samples during the nine different depth rainfall events. In Fig 3, the CLQ of $\mathrm{NH}_{4}{ }^{+}-\mathrm{N}$ in all the EGR devices outflow samples during the nine different depth rainfall events is negative, denoting the $\mathrm{NH}_{4}{ }^{+}-\mathrm{N}$ interception effects for the rainfall runoff. The average CLQ of $\mathrm{NH}_{4}{ }^{+}-\mathrm{N}$ in the six EGR devices during the entire simulated rainfall experiment was $-107.46 \mathrm{mg}$. This is due to the strong ion exchange capacity of the substrate in the EGR substrate layer. It can effectively intercept the $\mathrm{NH}_{4}{ }^{+}-\mathrm{N}$ in rainfall runoff in the extremely short contact time between the runoff and substrate (Guo et al. 2018). The layered EGR devices of PVL and PVGL exhibited stronger $\mathrm{NH}_{4}{ }^{+}-\mathrm{N}$ interception capacity for rainfall runoff than other devices. The $\mathrm{NH}_{4}{ }^{+}-\mathrm{N}$ interception quantity of PVL and PVGL during the entire simulated rainfall process was 114.613 and $121.364 \mathrm{mg}$, respectively. This is similar to the result of Wang et al. (2017), who found that EGR with a layered substrate layer has a stronger purification capacity for $\mathrm{NH}_{4}{ }^{+}-\mathrm{N}$ in rainfall runoff than EGR without the layered substrate layer. This is because compared to other mixed substrate devices, although the layered EGR upper nutrient substrate layer may have $\mathrm{NH}_{4}{ }^{+}-\mathrm{N}$ leaching risk in the peat soil after the runoff scouring, the lower adsorption substrate layer can still efficiently adsorb $\mathrm{NH}_{4}{ }^{+}-\mathrm{N}$ in the runoff of the upper layer. Compared to $\mathrm{PV}, \mathrm{PVG}$ exhibited a significant $\mathrm{NH}_{4}{ }^{+}-\mathrm{N}$ interception capacity, which may be because green zeolite has a higher affinity for $\mathrm{NH}_{4}{ }^{+}-\mathrm{N}$ in rainfall runoff than vermiculite. Alternately, it may be because the two adsorption substrates in the substrate layer have a synergistic purification effect on $\mathrm{NH}_{4}{ }^{+} \mathrm{N}$ in rainfall runoff, which exhibits better $\mathrm{NH}_{4}{ }^{+} \mathrm{N}$ interception effect in rainfall runoff than a single adsorption substrate (Piscitelli et al. 2018). The total CLQ of $\mathrm{NH}_{4}{ }^{+}-\mathrm{N}$ for PVG and PVGP is similar because the $\mathrm{NH}_{4}{ }^{+}-\mathrm{N}$ interception in rainfall runoff is highly dependent on the substrate adsorption capacity. The effect of PAM addition to the PVGP substrate layer to form a granular structure for intercepting $\mathrm{NH}_{4}{ }^{+}-\mathrm{N}$ leaching in the substrate layer is not obvious, and PAM is equivalent to a $\mathrm{NH}_{4}{ }^{+}-\mathrm{N}$ pollution source, which increases the $\mathrm{NH}_{4}{ }^{+}-\mathrm{N}$ concentration of the EGR outflow during the runoff scouring process. Note that in the six heavy rain events, the CLQ of $\mathrm{NH}_{4}{ }^{+}-\mathrm{N}$ in PVB outflow is only better than that of PV, which is $-34.086 \mathrm{mg}$. However, during the nine different depths rainfall events, except for the two best-performing layered EGR devices, PVB exhibited a better $\mathrm{NH}_{4}{ }^{+}-\mathrm{N}$ interception capacity for rainfall runoff than other devices, with a cumulative interception quantity of $109.859 \mathrm{mg}$. This 

layer are effective in improving the $\mathrm{NH}_{4}{ }^{+}-\mathrm{N}$ interception capacity of EGR, which is particularly significant in terrestrial rain and downpour events.

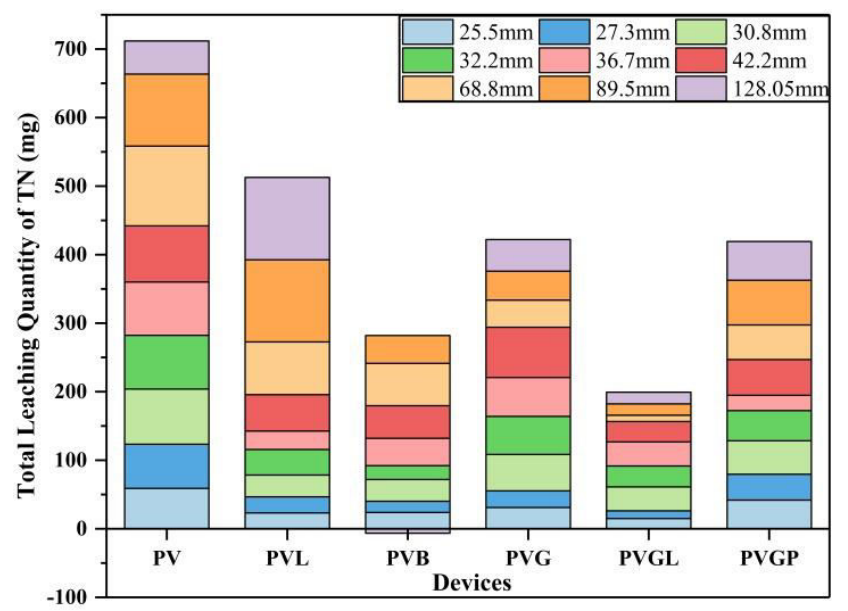

Fig 4 The CLQ of TN in the six EGR devices outflow samples during the nine different depth rainfall events

Fig 4 shows the CLQ of TN in the six EGR devices outflow samples during the nine different depth rainfall events. In Fig 4, except for PVB in the $128.05 \mathrm{~mm}$ rainfall event, the CLQ of TN is lower than the rainfall, which is manifested as a slight TN interception effect in rainfall runoff. Different degrees of TN leaching occurred during the nine different depth rainfall events for the other EGR devices. The average total CLQ of TN in the six EGR devices outflow was $423.488 \mathrm{mg}$. This denotes that EGRs are usually a nitrogen pollution source under rainfall processing and that biochar can improve the nitrogen leaching interception ability of EGRs under downpour events. This is similar to the results of Zhang et al. (2019). Compared to PVL, which is also a layered configuration, PVGL afforded a better TN interception effect. The total CLQ of TN in the PVGL outflow during the entire simulated rainfall process was the lowest (199.397 mg). Furthermore, the total CLQ of TN in the PVG outflow was lower than that of PV, indicating that the combination of vermiculite and green zeolite configures in the substrate layer with direct mixing or layered configuration had better nitrogen interception capacity than single vermiculite. Xu et al. (2021) found that single vermiculite, as the substrate layer, has better rainfall runoff interception efficiency than single green zeolite. Therefore, the selection of a mixed adsorption substrates instead of a single adsorption substrate in the substrate layer can effectively improve the EGR ability to intercept nitrogen in rainfall runoff. The CLQ of TN in PVG and PVGP outflows during the entire simulated rainfall were almost identical, which were 422.000 and $419.314 \mathrm{mg}$, respectively. Thus, PAM addition in the substrate layer to form a granular structure inhibited the TN leaching effect during the scouring process and improved the EGR ability to intercept TN in rainfall runoff, but the CLQ of $\mathrm{TN}$ in the EGR device outflow did not reduce. Therefore, the addition of PAM as a modifier in EGR substrate layers does not improve the TN interception effect in rainfall runoff. 


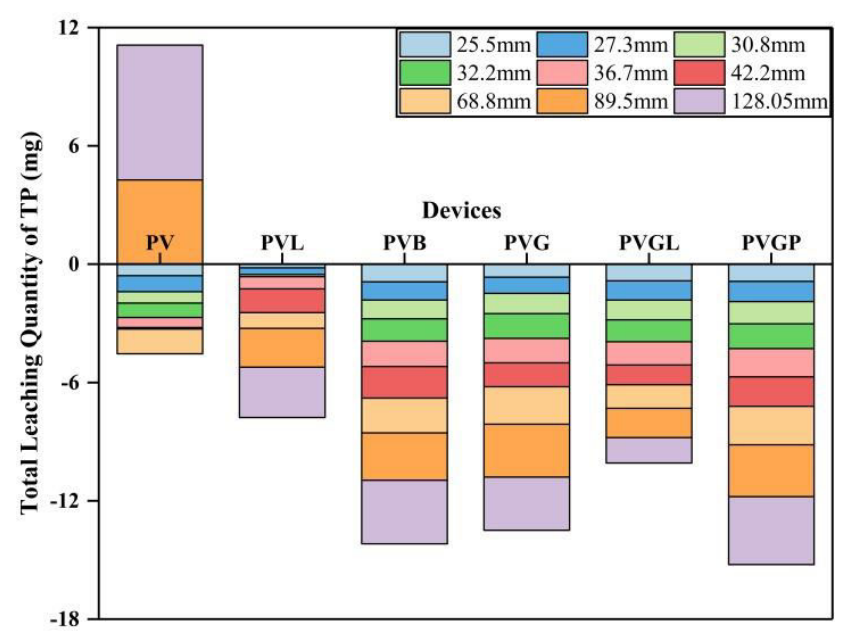

Fig 5 The CLQ of TP in the six EGR devices outflow samples during the nine different depth rainfall events

Fig 5 shows the CLQ of TP in the six EGR devices outflow samples during the nine different depth rainfall events. In Fig 5, except for PV, all other EGR devices display the ability to intercept TP in rainfall runoff during nine different depth simulated rainfall events, and the CLQ of TP in PV was $6.565 \mathrm{mg}$. Among them, the CLQ of TP in PV outflows in the two rainfall events of 89.5 and $128.05 \mathrm{~mm}$ was extremely significant: 4.271 and $6.835 \mathrm{mg}$, respectively. This may be because the structure of the substrate layer afforded by the direct mixing of peat soil and vermiculite is easily damaged by runoff scouring under high intensity rainfall events, and a large amount TP in peat soil is leached. Although the layered EGRs of PVL and PVGL exhibited the TP interception effect in rainfall runoff during the entire simulated rainfall process, they are not significant compared to those of PVB, PVG and PVGP. Among them, only PVG with direct mixing exhibited good TP leaching inhibitory ability, implying that the layered configuration is not the most effective substrate layer configuration for TP interception in rainfall runoff. This may be because the formation of TP was the outflow is mainly particulate P; thus, the adsorption substrate could not exert efficient TP adsorption capacity. Both EGR devices with the addition of PVB and PVGP modifiers showed a significant TP interception effect in rainfall runoff, indicating that the addition of modifiers to improve the substrate layer structure can effectively alleviate the phosphorus leaching phenomenon in the EGRs. This is similar to the results of Soinne et al. (2014). Especially, PVGP with PAM added performs better than other EGR devices, because PAM promotes peat soil, vermiculite, and green zeolite to form a stable granular structure and inhibits TP leaching during runoff scouring. Additionally, Chai et al. (2018) concluded that TP in EGR outflow is mainly affected by the phosphorus-rich substrate. Therefore, the TP interception in rainfall runoff by EGR mainly depends on the leaching inhibition of the substrate layer and less on the substrate adsorption capacity. 


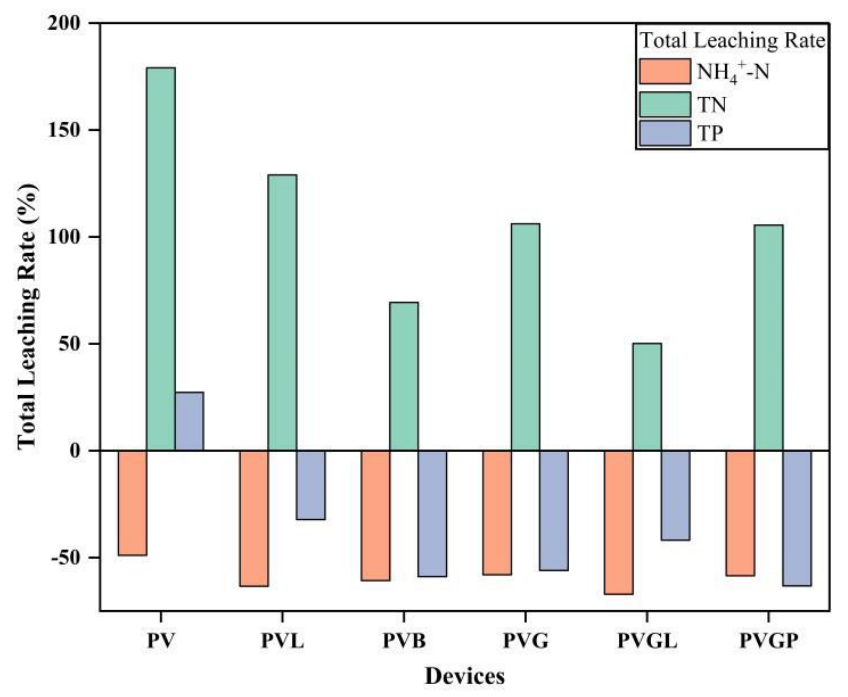

Fig 6 The TLR of $\mathrm{NH}_{4}{ }^{+}-\mathrm{N}, \mathrm{TN}$ and TP in the six EGR devices outflow samples during the entire simulated rainfall process

Fig 6 shows the TLR of $\mathrm{NH}_{4}{ }^{+}-\mathrm{N}, \mathrm{TN}$ and TP in the six EGR devices outflow samples during the entire simulated rainfall process. In Fig 6, the EGRs with different substrate layer configurations show the interception effect of $\mathrm{NH}_{4}{ }^{+}-\mathrm{N}$ and the $\mathrm{TN}$ leaching effect in rainfall runoff. The average total interception rate of $\mathrm{NH}_{4}{ }^{+}-\mathrm{N}$ was $59.47 \%$, and the average TLR of TN was $106.53 \%$. Among the six EGR devices, only PV exhibited the TP leaching effect and the TLR of TP was $27.25 \%$. Additionally, PV exhibited the largest TLR of TN and the lowest total interception rate of $\mathrm{NH}_{4}{ }^{+}-\mathrm{N}: 179.08 \%$ and $48.93 \%$, respectively. PVG is also an EGR device with direct mixing substrate layer configuration, but it exhibited a significant pollution interception effect compared to PV during the entire simulated rainfall experiment. Furthermore, PVGL exhibited a similar situation relative to PVL with the same layered configuration. This shows that in the construction of the EGR substrate layer, two or more adsorption substrates should be selected as far as possible. If allowed by the load requirements, a larger proportion of green zeolite should be selected instead of vermiculite so that EGR can more efficiently intercept pollution in rainfall runoff. For the three different substrate layer configurations EGR devices of PV, PVL and PVB with peat soil and vermiculite as substrate layer, the addition of biochar as a modifier was the best substrate layer configuration for improving the EGR pollution interception capacity in rainfall runoff. PVB exhibited better $\mathrm{NH}_{4}{ }^{+} \mathrm{N}$ and TN interception effects in rainfall runoff than PVGP under the adverse conditions where the adsorption substrate is only vermiculite, showing that biochar can be used as an excellent modifier for enhancing the rainfall runoff pollution interception capacity of EGRs. For the three different substrate layer configuration EGR devices of PVG, PVGL and PVGP with peat soil, vermiculite and green zeolite as substrate layers, the addition of PAM as a modifier was not the optimal substrate layer configuration as it did not improve the EGR pollution interception capacity in rainfall runoff. However, PVGL yielded significant $\mathrm{NH}_{4}{ }^{+}-\mathrm{N}$ and TN interception effects in rainfall runoff. This shows that although PAM addition promotes the formation of the granular structure in the EGR substrate layer and inhibits the EGR TP leaching ability, it generates additional nitrogen pollution. Thus, it is not a good modifier for the EGR substrate layer. 
(1) The six EGR devices with different substrate layer configurations showed the interception effect of $\mathrm{NH}_{4}{ }^{+} \mathrm{N}$ and the TN leaching effect in rainfall runoff. The average total interception quantity and rate of $\mathrm{NH}_{4}{ }^{+}-\mathrm{N}$ were $107.46 \mathrm{mg}$ and $59.47 \%$, respectively, and the average total CLQ and TLR of TN were $423.488 \mathrm{mg}$ and $106.53 \%$, respectively. PV was the only EGR device that exhibited TP leaching during the entire simulated rainfall experiment. The total CLQ and TLR were $6.565 \mathrm{mg}$ and $27.25 \%$, respectively. This is because the substrate layer structure of peat soil and vermiculite with direct mixing is easily damaged under high intensity rainfall events and a large amount of TP is leached in the peat soil.

(2) The EGR using green zeolite mixed with vermiculite as the adsorption substrate exhibited a significantly higher rainfall runoff pollution interception capacity than the EGR using single vermiculite as the adsorption substrate. This is because the multiple adsorption substrates have a synergistic effect on the adsorption and interception of pollutants.

(3) Compared to other EGR devices, PVL and PVGL as EGRs with layered configuration substrate layers exhibited better $\mathrm{NH}_{4}{ }^{+}-\mathrm{N}$ interception capacity due to the efficient $\mathrm{NH}_{4}{ }^{+}-\mathrm{N}$ adsorption character of the unique lower adsorption layer. The total interception quantities of $\mathrm{NH}_{4}{ }^{+}-\mathrm{N}$ for PVL and PVGL were $114.613 \mathrm{mg}$ and $121.364 \mathrm{mg}$, respectively.

(4) PVB exhibited better $\mathrm{NH}_{4}{ }^{+}-\mathrm{N}$ and TN interception effects in rainfall runoff than PVGP under the adverse conditions where the adsorption substrate is only vermiculite. Furthermore, biochar addition greatly slowed down the TP leaching effect of the substrate layer, implying that biochar can be used as an excellent modifier to enhance the rainfall runoff pollution interception capacity of EGRs. However, PAM addition in the EGR substrate layer generated additional nitrogen pollution and aggravated the nitrogen leaching phenomenon in the EGR outflow. However, the built-up granular structure substrate layer exhibited a significant TP leaching inhibition effect.

\section{Reference}

Abualfaraj, N., Cataldo, J., Elborolosy, Y., Fagan, D., Woerdeman, S., Carson, T., Montalto, F.A., 2018. Monitoring and modeling the long-term rainfall-runoff response of the Jacob K. Javits center green roof. Water. 10(11), 1494.

Chai, H.X., Tang, Y., Su, X.J., Wang, W.J., Lu, H., Shao, Z.Y., He, Q., 2018. Annual variation patterns of the effluent water quality from a green roof and the overall impacts of its structure. Environmental Science and Pollution Research. 25(30), 30170-30179.

Chen, H.M., Ma, J.Y., Wei, J.X., Gong, X., Yu, X.C., Guo, H., Zhao, Y.W., 2018. Biochar increases plant growth and alters microbial communities via regulating the moisture and temperature of green roof substrates. Science of the Total Environment. 635, 333-342.

Eksi, M., Rowe, D.B., 2016. Green roof substrates: Effect of recycled crushed porcelain and foamed glass on plant growth and water retention. Urban Forestry \& Urban Greening. 20, 81-88.

Gong, Y.W., Yin, D.K., Li, J.Q., Zhang, X.W., Wang, W.H., Fang, X., Shi, H.H., Wang, Q., 2019. Performance assessment of extensive green roof runoff flow and quality control capacity based on pilot experiments. Science of the total environment. 687, 505-515.

Gong, Y.W., Yin, D.K., Fang, X., Li, J.Q., 2018. Factors Affecting Runoff Retention Performance of Extensive 
Green Roofs. Water. 10(9), 1217.

Gong, Y.W., Yin, D.K., Fang, X., Zhai, D.D., Li, J.Q., 2018. Rainwater retention effect of extensive green roofs monitored under natural rainfall events-a case study in Beijing. Hydrology Research. 49(6), 1773-1787.

Guo, J.K., Zhang, Y.T., Che, S.Q., 2018. Performance analysis and experimental study on rainfall water purification with an extensive green roof matrix layer in shanghai, china. Water Science and Technology. 77(3), 670-681.

Hill, J., Sleep, B., Drake, J., Fryer, M., 2019. The effect of intraparticle porosity and interparticle voids on the hydraulic properties of soilless media. Vadose Zone Journal. 18, 1-13.

Huang, S., Garg, A., Mei, G.X., Huang, D.S., Chandra, R.B., Sadasiv, S.G., 2020. Experimental study on the hydrological performance of green roofs in the application of novel biochar. Hydrological Processes. 34(23), 4512-4525.

Huang, Y.Y., Chen, C.T., Liu, W.T., 2018. Thermal performance of extensive green roofs in a subtropical metropolitan area. Energy and Buildings. 159, 39-53.

Karczmarczyk, A., Bus, A., Baryła, A., 2018. Phosphate leaching from green roof substrates-can green roofs pollute urban water bodies?. Water. 10(2), 199.

Liu, W., Feng, Q., Chen, W.P., Wei, W., Deo, R.C., 2019. The influence of structural factors on stormwater runoff retention of extensive green roofs: new evidence from scale-based models and real experiments. Journal of Hydrology. 569, 230-238.

Ouyang, W., Huang, W.J., Peng, W., Hao, F.H., Yu, Y.Y., 2016. Optimization of typical diffuse herbicide pollution control by soil amendment configurations under four levels of rainfall intensities. Journal of Environmental Management. 175, 1-8.

Piscitelli, L., Rivier, P.A., Mondelli, D., Miano, T., Joner, E.J., 2018. Assessment of addition of biochar to filtering mixtures for potential water pollutant removal. Environmental Science and Pollution Research. 25, 2167-2174.

Shafique, M., Kim, R., Kyung-Ho, K., 2018. Green roof for stormwater management in a highly urbanized area: the case of Seoul, Korea. Sustainability. 10(3), 584.

Santos, P.L.F.D., Castilho, R.M.M.D., 2018. Floriferous herbaceous and substrates for use on extensive green roofs. Ornamental Horticulture. 24(3), 275-282.

Sepaskhah, A.R., Shahabizad, V., 2010. Effects of water quality and pam application rate on the control of soil erosion, water infiltration and runoff for different soil textures measured in a rainfall simulator. Biosystems Engineering. 106(4), 513-520.

Soinne, H., Hovi, J., Tammeorg, P., Turtola, E., 2014. Effect of biochar on phosphorus sorption and clay soil aggregate stability. Geoderma. 219-220, 162-167.

Todorov, D., Driscoll, C.T., Todorova, S., Montesdeoca, M., 2018. Water quality function of an extensive vegetated roof. Science of the Total Environment. 625, 928-939.

Thuring, C. E., Dunnett, N. P., 2019. Persistence, loss and gain: characterising mature green roof vegetation by functional composition. Landscape \& Urban Planning. 185, 228-236.

Tuttolomondo, T., Fascella, G., Licata, M., Schicchi, R., Gennaro, M.C., La Bella, S., Leto, C., Aprile, S., 2018. Studies on sedum taxa found in sicily (italy) for mediterranean extensive green roofs. Italian Journal of Agronomy. 13, 1077.

Tran, S., Lundholm, J.T., Staniec, M., Robinson, C.E., Smart, C.C., Voogt, J.A., O’Carroll, D.M., 2018. Plant survival and growth on extensive green roofs: a distributed experiment in three climate regions. Ecological Engineering. 127, 494-503.

Todorov, D., Driscoll, C.T., Todorova, S., 2018. Long-term and seasonal hydrologic performance of an extensive green roof. Hydrological Processes. 32, 2471-2482. 
Vijayaraghavan, K., Reddy, D.H.K., Yun, Y.S., 2018. Improving the quality of runoff from green roofs through synergistic biosorption and phytoremediation techniques: a review. Sustainable Cities and Society. 46, 101381. Wang, X.O., Tian, Y.M., Zhao, X.H., 2017. The influence of dual-substrate-layer extensive green roofs on rainwater runoff quantity and quality. Science of the Total Environment. 592, 465-476.

465 Xu, C., Liu, Z.H., Cai, G.J., Zhan, J., 2021. Experimental study on the selection of common adsorption substrates for extensive green roofs (egrs). Water Science and Technology. 83(4), 961-974. Zhou, D.M., Liu, Y.X., Hu, S.S., Hu D.Y., Neto, S., Zhang Y., 2019. Assessing the hydrological behaviour of large-scale potential green roofs retrofitting scenarios in Beijing. Urban Forestry \& Urban Greening. 40, 105-113. Zhang, W., Zhong, X., Che, W., 2018. Nutrient leaching from extensive green roofs with different substrate compositions: a laboratory study. Water Science and Technology. 77(3-4), 1007-1014.

471 Zhang, Q.Q., Miao, L.P., Wang, H.W., Wang, L., 2019. Analys is of the effect of green roof substrate amended with biochar on water quality and quantity of rainfall runoff. Environmental Monitoring and Assessment. 191, 304. 